\title{
OPEN Effect of gamma irradiation on filtering facepiece respirators and SARS-CoV-2 detection
}

\author{
Khaled Al-Hadyan ${ }^{1 凶}$, Ghazi Alsbeih ${ }^{1 凶}$, Najla Al-Harbi ${ }^{1}$, Sara Bin Judia ${ }^{1}$, Maha Al-Ghamdi ${ }^{1}$, \\ Akram Almousa ${ }^{1}$, Ibtihaj Alsharif ${ }^{2}$, Razan Bakheet ${ }^{3}$, Khaldoun Al-Romaih', \\ Maha Al-Mozaini ${ }^{2}$, Salem Al-Ghamdi ${ }^{4}$, Belal Moftah ${ }^{1}$ \& Rashed Alhmaid ${ }^{5}$
}

To cope with the shortage of filtering facepiece respirators (FFRs) during the coronavirus (COVID-19) pandemic, healthcare institutions were forced to reuse FFRs after applying different decontamination methods including gamma-irradiation (GIR). The aim of this study was to evaluate the effect of GIR on the filtration efficiency (FE) of FFRs and on SARS-CoV-2 detection. The FE of 2 FFRs types (KN95 and N95-3 M masks) was assessed at different particle sizes (0.3-5 $\mu \mathrm{m})$ following GIR (0-15 kGy) delivered at either typical $(1.65 \mathrm{kGy} / \mathrm{h})$ or low $(0.5088 \mathrm{kGy} / \mathrm{h})$ dose rates. The detection of two SARSCoV-2 RNA genes (E and RdRp4) following GIR (0-50 kGy) was carried out using RT-qPCR assay. Both masks showed an overall significant $(P<0.001)$ reduction in FE with increased GIR doses. No significant differences were observed between GIR dose rates on FE. The GIR exhibited significant increases $(P \leq 0.001)$ in the cycle threshold values $(\Delta C \mathrm{t})$ of both genes, with no detection following high doses. In conclusion, complete degradation of SARS-CoV-2 RNA can be achieved by high GIR ( $\geq 30 \mathrm{kGy}$ ), suggesting its potential use in FFRs decontamination. However, GIR exhibited adverse effects on FE in dose- and particle size-dependent manners, rendering its use to decontaminate FFRs debatable.

The filtering facepiece respirators (FFRs), including N95 masks, play an important role in infection prevention and control by reducing the airborne transmission of infectious illnesses from patients to health practitioners ${ }^{1,2}$. The N95 mask is a high efficacy single-use FFR that can block up to $95 \%$ of particles of $\geq 0.3 \mu \mathrm{m}$ in diameter. The N95 mask is approved by the United States Food and Drug Administration (FDA) and the National Institute for Occupational Safety and Health (NIOSH) for use as personal protective equipment (PPEs) in medical settings ${ }^{1,2}$.

Due to the global shortage of N95 masks during the outbreak of Coronavirus Disease (COVID-19) caused by the emerging severe acute respiratory syndrome coronavirus 2 (SARS-CoV-2), NIOSH has issued a recommended guidance for the extended use and limited reuse of N95 masks in emergency medical settings ${ }^{3}$. Although the NIOSH guidance can significantly reduce the consumption of N95 masks during the pandemic, concerns about these policies have been raised ${ }^{4,5}$. These concerns are related to the long survival of the SARS-CoV-2 virus on the outer layer of N95 masks, leading to cross-contamination between staff and patients ${ }^{4,5}$. Therefore, decontamination and subsequent reuse of the N95 masks were highly recommended to cope with the expected shortage in such a pandemic.

There are six well-characterized N95 decontamination procedures including vapor hydrogen peroxide (VHP), ethylene oxide, moist heat incubation, microwave oven, ultraviolet germicidal irradiation (UVGI), and gamma irradiation (GIR) ${ }^{6-10}$. Although the USA Centers for Disease Control (CDC) did not approve the routine decontamination of N95 masks, it released emergency guidelines on the N95 decontamination methods and indicated that UVGI, VHP and moist heat had shown the most promising results ${ }^{7}$. However, these three methods have certain logistical and technical limitations including the small capacity, the limited penetration and the high risk of pathogen cross-contamination should the used FFRs be removed from their biosafety container/bag and handled individually during the decontamination process ${ }^{6-10}$.

Hypothetically, GIR has several advantages among other decontamination methods such as better penetration, better certainty of sterility and independence from temperature and pressure conditions ${ }^{11}$. However, concerns have been raised regarding the adverse effect of GIR on the physical properties of FFRs materials, in particular

${ }^{1}$ Biomedical Physics Department, King Faisal Specialist Hospital and Research Centre (KFSH\&RC), Riyadh, Saudi Arabia. ${ }^{2}$ Infection and Immunity Department, KFSH\&RC, Riyadh, Saudi Arabia. ${ }^{3}$ Translational Genomics Department, KFSH\&RC, Riyadh, Saudi Arabia. ${ }^{4}$ Infection Control and Hospital Epidemiology Department, KFSH\&RC, Riyadh, Saudi Arabia. ${ }^{5}$ General Corporate Consultancy Department, KFSH\&RC, Riyadh, Saudi Arabia. ${ }^{\circledR}$ email: Khadyan@kfshrc.edu.sa; galsbeih@kfshrc.edu.sa 


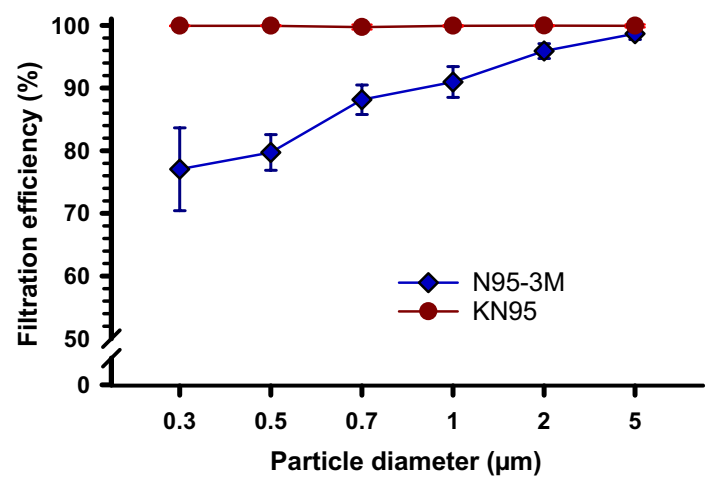

Figure 1. Filtration efficiency (FE) of KN95 and N95-3M FFRs. KN95 ( $=10)$ and N95-3M ( $=10)$ FFRs were applied to FE evaluation for different particle sizes $(0.3-5 \mu \mathrm{m})$ using AeroTrak particle counter. Symbols represent the mean and error bars indicate the standard deviation. The overall FE of KN95 masks was significantly higher $(P=0.022)$ than N95-3M masks. At each particle size, the KN95 masks' FE was significantly higher $(P \leq 0.001)$ than N95-3M masks.

polymer fabric, a major component in manufacturing FFRs ${ }^{12-15}$. Briefly, the FFRs filter fabrics are made mainly by polypropylene (PP), a thermoplastic polymer used in a wide variety of applications, in addition to other secondary components such as nylon, cotton and polyester ${ }^{14}$. The GIR was shown to cause substantial adverse alterations in the physical characteristics of PP, such as enhanced polymer oxidation, polymer chain scission or cross-linking, which can degrade the PP mechanical filtration performance and its clinical protection ${ }^{12,13,15}$. Regardless of these concerns, recent studies during the COVID-19 pandemic reconsider the potential deployment of GIR in the decontamination and reuse of the FFRs ${ }^{6,16-19}$.

Since 1971, GIR has been used to inactivate many types of microorganisms, including single-stranded RNA viruses ${ }^{20,21}$. The mechanism of virus inactivation using GIR is thought to fall into direct and indirect categories $^{22-24}$. Direct virus inactivation is mainly caused by radiolytic cleavage or cross-linking of genetic material. Indirect virus inactivation is caused by the oxidative damage of genetic material caused by free radicals issued from the radiolysis of water. The major molecular target of both mechanisms is believed to be the nucleic acids, whereas radiation damages to proteins and lipids in the viral envelope are believed to play a minor role in the virus inactivation ${ }^{25-27}$.

The viruses of the corona family such as SARS-CoV (including SARS-CoV-2) and Middle East respiratory syndrome coronavirus (MERS-CoV) were reported to be inactivated by a dose of $10 \mathrm{kGy}$, although lower doses have not been extensively studied ${ }^{28-31}$. Only one study reported that a dose of $0.15 \mathrm{kGy}$, a dose not expected to inactivate viruses, was insufficient to inactivate active cultured SARS-CoV ${ }^{32}$.

To our knowledge, no attempt has been made so far to study the effect of low dose rate GIR on either SARSCoV-2 activity or the filtration efficiency (FE) of FFRs. Therefore, the aim of this study was to evaluate the effect of typical and low dose rates GIR on the FE of two common FFR types, KN95 and 3M-N95 masks, hypothesizing that the eventual adverse effect of GIR on FFRs could be minimized by using low dose rate GIR. Simultaneously, the study explored the capability of low dose rate GIR to sterilize infected FFRs by evaluating the detectability of SARS-CoV-2 RNA following gamma-irradiation using reverse transcription quantitative real-time polymerase chain reaction (RT-qPCR) assay.

\section{Results}

Initial filtration efficiency (FE) of FFRs. 0The results of the initial FE (before any treatment) of KN95 and N95-3M masks are presented in Fig. 1. The KN95 masks exhibited constantly higher FE $(\geq 99.74 \%)$ at all particle sizes (PSs) than the N95-3M masks (77.1-98.7\%). Although the FE of the N95-3M mask increased progressively with increasing the PSs, it showed mediocre $(\leq 91.0 \%) \mathrm{FE}$ at small PSs $(0.3-1 \mu \mathrm{m})$ compared to larger particles $(2$ and $5 \mu \mathrm{m}$ ) which showed satisfactorily FE between 95.9 and $98.7 \%$. Statistically, the paired t-test showed that the overall mean FE (at all particle sizes) of KN95 was significantly higher than N95-3M masks (two-tailed $P$-value $=0.022$ ). Furthermore, the t-test showed that the individual FE at each PS was significantly higher $(P \leq 0.001)$ for KN95 compared to N95-3M masks.

Filtration efficiency (FE) of FFRs following gamma irradiation (GIR). The FE of KN95 and 3M-N95 masks was assessed following typical $(1.65 \mathrm{kGy} / \mathrm{h})$ and low $(0.5088 \mathrm{kGy} / \mathrm{h})$ dose rates GIR at PSs of $0.3,0.5,0.7$, 1,2 and $5 \mu \mathrm{m}$. Results are presented in Fig. 2. The FE displayed dose- and size-dependent decline for 0.3, 0.5, 0.7, 1 and $2 \mu \mathrm{m}$ particles sizes, with some particularities for each mask type and dose rate. As for the $5 \mu \mathrm{m}$ PS, the FE showed little or no decrease with increasing GIR dose.

Filtration efficiency (FE) of FFRs following typical dose rate gamma irradiation. The highest decreases in FE of KN95 and N95-3M masks were observed following $15 \mathrm{kGy}$ at PSs of 0.5 and $0.3 \mu \mathrm{m}$, with percentage decreases of $18.5 \%$ and $18.2 \%$, respectively (Supplementary Table S1). Statistically, the average FE values of KN95 masks 


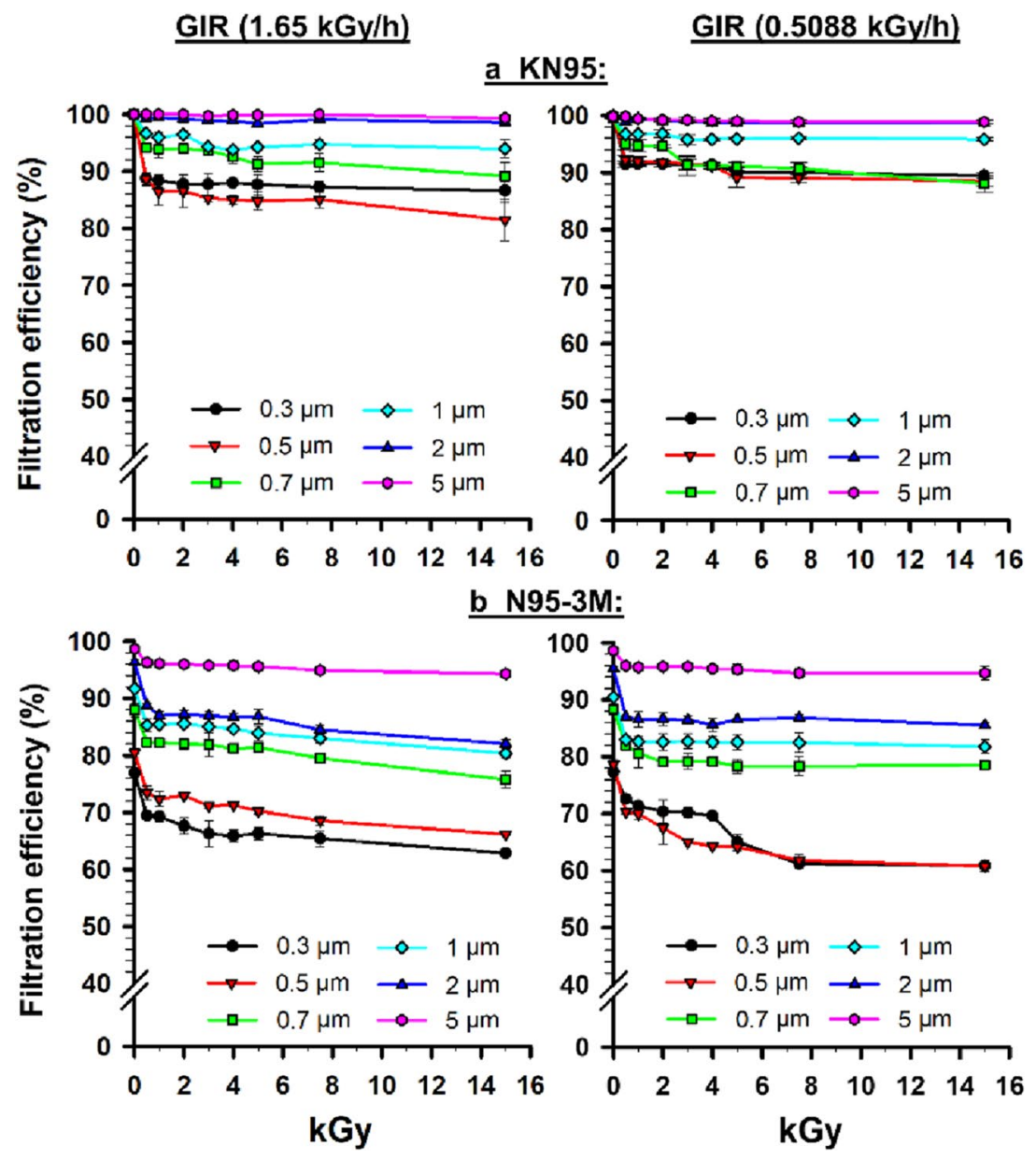

Figure 2. Filtration efficiency (FE) of a. KN95 and b. N95-3M masks for different particle sizes $(0.3-5 \mu \mathrm{m})$ following gamma irradiation (GIR) at either typical $(1.65 \mathrm{kGy} / \mathrm{h})$ or low $(0.5088 \mathrm{kGy} / \mathrm{h})$ dose rates. Symbols represent the mean and error bars indicate the standard error. Statistically, both masks showed an overall significant $(P<0.001)$ reduction in $\mathrm{FE}$ with increased radiation doses, for both dose rates. Pairwise comparisons for KN95 masks irradiated with typical gamma radiation: particle sizes of $0.3,0.5,0.7$ and $1 \mu \mathrm{m}$ versus 2 and $5 \mu \mathrm{m}$ were significant $(P \leq 0.016)$; particle sizes of 0.3 and $0.5 \mu \mathrm{m}$ versus 0.7 and $1 \mu \mathrm{m}$ were significant $(P \leq 0.002)$. Pairwise comparison for KN95 masks irradiated with low gamma radiation: $0.3 \mu \mathrm{m}$ versus $5 \mu \mathrm{m}$ $P=0.001 ; 0.5 \mu \mathrm{m}$ versus $5 \mu \mathrm{m} P=0.002 ; 0.7 \mu \mathrm{m}$ versus $5 \mu \mathrm{m} P=0.002 ; 0.3 \mu \mathrm{m}$ versus $2 \mu \mathrm{m} P=0.014 ; 0.5 \mu \mathrm{m}$ versus $2 \mu \mathrm{m} P=0.020 ; 0.7 \mu \mathrm{m}$ versus $2 \mu \mathrm{m} P=0.020$. Pairwise comparison for N95-3M masks irradiated with typical gamma radiation: particle sizes of $0.3,0.5,0.7,1$ and $2 \mu \mathrm{m}$ vs. $5 \mu \mathrm{m}$ were significant $(P<0.001)$; particle sizes of $0.3,0.5,0.7$ and $1 \mu \mathrm{m}$ versus $2 \mu \mathrm{m}$ were significant $(P \leq 0.002)$; particle sizes of $0.3,0.5$ and $0.7 \mu \mathrm{m}$ versus $1 \mu \mathrm{m}$ were significant $(P<0.001) ; 0.3$ and $0.5 \mu \mathrm{m}$ versus $0.7 \mu \mathrm{m}$ were significant $(P<0.001) ; 0.3 \mu \mathrm{m}$ versus $0.5 \mu \mathrm{m}$ $P<0.001$. Pairwise comparison for N95-3 M masks irradiated with low gamma radiation: particle sizes of 0.3 , $0.5,0.7,1$ and $2 \mu \mathrm{m}$ versus $5 \mu \mathrm{m}$ were significant $(P<0.001)$; particle sizes of $0.3,0.5,0.7$ and $1 \mu \mathrm{m}$ versus $2 \mu \mathrm{m}$ were significant $(P \leq 0.005)$; particle sizes of 0.3 and $0.5 \mu \mathrm{m}$ versus 0.7 and $1 \mu \mathrm{m}$ were significant $(P<0.001)$.

were significantly lower than control at GIR doses of 4, 5 and $15 \mathrm{kGy}$ (One Way Repeated Measure Analysis of Variance, $P \leq 0.030$ ), whereas the average FE values of N95-3M masks were significantly lower than control at GIR dose of 4, 5, 7.5 and $15 \mathrm{kGy}(P \leq 0.025$, Table 1$)$.

For the KN95 masks, the FE at PSs of 2 and $5 \mu \mathrm{m}$ was almost stable (FE98.3-100\%) following GIR (Fig. 2-A, left panel). However, a gradual decrease in FE at PSs between 0.3 and $1 \mu \mathrm{m}$ was observed to reach $81.5 \%$ following 15 Gy GIR. Statistically, the KN95 masks showed an overall significant reduction $(P<0.001)$ in FE with increased GIR doses. In particular, the FE of irradiated KN95 masks at $0.3,0.5,0.7$ and $1 \mu \mathrm{m}$ was significantly lower than at $5 \mu \mathrm{m}(P \leq 0.001)$. Similarly, FE of irradiated KN95 masks at $0.30 .5,0.7$ and $1 \mu \mathrm{m}$ was significantly lower than $2 \mu \mathrm{m}(P \leq 0.016)$. Furthermore, FE of irradiated KN95 masks at 0.3 and $0.5 \mu \mathrm{m}$, overall GIR doses, was significantly lower than $\mathrm{FE}$ at 0.7 and $1 \mu \mathrm{m}(P \leq 0.002)$.

For the N95-3M masks, the FE at PS of $5 \mu \mathrm{m}$ was more stable (FE94.3-98.7\%) than other PSs that showed a progressive decrease to reach $62.9 \%$ following 15 Gy GIR (Fig. 2-B, left panel). Statistically, the N95-3M masks showed an overall significant reduction $(P<0.001)$ in FE with increasing GIR doses. In particular, FE of irradiated N95-3M masks at each PS was significantly different from another $(P \leq 0.002)$. 


\begin{tabular}{|c|c|c|c|c|c|c|c|c|}
\hline \multirow[b]{3}{*}{ Dose (kGy) } & \multicolumn{4}{|l|}{ KN95 } & \multicolumn{4}{|l|}{ N95-3M } \\
\hline & \multicolumn{2}{|c|}{ Typical dose rate } & \multicolumn{2}{|c|}{ Low dose rate } & \multicolumn{2}{|c|}{ Typical dose rate } & \multicolumn{2}{|c|}{ Low dose rate } \\
\hline & FE average $^{\star}$ & $P$ value & FE average $^{*}$ & $P$ value & FE average ${ }^{*}$ & $P$ value & FE average $^{\star}$ & $P$ value \\
\hline 0 & 100.0 & & 99.9 & & 89.8 & & 88.1 & \\
\hline 0.5 & 95.4 & 0.999 & 95.9 & 0.955 & 83.8 & 0.995 & 81.8 & $<0.001$ \\
\hline 1 & 94.9 & 0.943 & 95.7 & 0.955 & 83.8 & 0.868 & 81.2 & $<0.001$ \\
\hline 2 & 95.2 & 0.890 & 95.7 & 0.687 & 83.7 & 0.868 & 80.3 & $<0.001$ \\
\hline 3 & 94.0 & 0.066 & 93.7 & 0.270 & 83.4 & 0.133 & 79.9 & $<0.001$ \\
\hline 4 & 93.1 & 0.030 & 93.6 & 0.012 & 82.9 & 0.025 & 79.5 & $<0.001$ \\
\hline 5 & 92.8 & 0.003 & 93.5 & 0.007 & 82.6 & 0.017 & 78.6 & $<0.001$ \\
\hline 7.5 & 93.2 & 0.13 & 93.3 & $<0.001$ & 81.2 & $<0.001$ & 77.5 & $<0.001$ \\
\hline 15 & 91.6 & $<0.001$ & 92.6 & $<0.001$ & 78.0 & $<0.001$ & 77.0 & $<0.001$ \\
\hline
\end{tabular}

Table 1. Filtration efficiency of KN95 and N95-3M masks before and after gamma radiation dose of 0-15 kGy. ${ }^{\star}$ The FE average is either a mean FE value if FE variables at all particle sizes $(0.3-5 \mu \mathrm{m})$ passed the normality test or a median FE value if FE variables failed the normality test.

Filtration efficiency (FE) of FFRs following low dose rate gamma irradiation. The highest decreases in FE of KN95 and N95-3M masks were observed following $15 \mathrm{kGy}$ at small PSs of $\leq 0.7$, with percentage decreases of $11.6 \%$ and $22.8 \%$, respectively (Supplementary Table S1). Statistically, the average FE values of the KN95 masks were significantly lower than control ( $0 \mathrm{kGy}$ ) at GIR doses of 4, 5, 7.5 and $15 \mathrm{kGy}$ (One Way Repeated Measure Analysis of Variance, $P \leq 0.012$ ), whereas the average FE values of N95-3M masks were significantly lower than control at all GIR doses $(P<0.001$; Table 1$)$.

For the KN95 masks, the FE at PSs of 2 and $5 \mu \mathrm{m}$ was almost stable (FE=98.6-99.9\%) following GIR (Fig. 2A, right panel). However, a decrease in FE (88.0-99.9\%) at PSs between 0.3 and $1 \mu \mathrm{m}$ was observed following GIR. Statistically, the KN95 masks exhibited an overall significant reduction $(P<0.001)$ in FE with increased GIR doses. In particular, the FE of irradiated KN95 masks at PSs of $0.3,0.5$, and $0.7 \mu \mathrm{m}$ was significantly lower than $\mathrm{FE}$ at $5 \mu \mathrm{m}(P \leq 0.002)$. Similarly, FE of irradiated KN95 masks at $0.3,0.5$, and $0.7 \mu \mathrm{m}$, over GIR, was significantly lower than $\mathrm{FE}$ at $2 \mu \mathrm{m}$ ( $P$-values were $0.014,0.020$ and 0.020 , respectively).

For N95-3M masks, the FE at a PS of $5 \mu \mathrm{m}$ was more stable $(\mathrm{FE}=94.7-98.6 \%)$ than at other PSs $(\mathrm{FE}=60.8-95.5 \%)$ following GIR (Fig. 2-B, right panel). Statistically, the N95-3M masks showed an overall significant reduction $(P<0.001)$ in FE with increased GIR doses. In particular, FE of irradiated N95-3M masks at $0.3,0.5,0.7,1$ and $2 \mu \mathrm{m}$ was significantly lower than FE at $5 \mu \mathrm{m}(P \leq 0.001)$. Similarly, FE of irradiated N95-3M masks at $0.3,0.5,0.7$ and $1 \mu \mathrm{m}$ was significantly lower than FE at $2 \mu \mathrm{m}(P \leq 0.001)$. Furthermore, FE of irradiated N95-3M masks at 0.3 and $0.5 \mu \mathrm{m}$, over all GIR doses, was significantly lower than FE at 0.7 and $1 \mu \mathrm{m}(P \leq 0.001)$.

Taking both dose rates together, the KN95 masks following GIR showed higher FE (81.5-100\%) than 3M-N95 masks (FE =60.8-98.6\%) (Fig. 2). The FE of both masks at large PSs (2 and $5 \mu \mathrm{m}$ ) was somewhat stable compared to FE at small PSs $(0.3-1 \mu \mathrm{m})$. In general, the FE values were decreased with the increased GIR doses. The highest decreases in FE of KN95 and N95-3M masks were observed following $15 \mathrm{kGy}$, with percentage decreases ranging between 0.60 and $22.8 \%$ (Supplementary Table $\mathrm{S} 1$ ).

For both dose rates, the average FE values of KN95 masks irradiated with 4, 5, 7.5 and 15 kGy were significantly $(P \leq 0.03)$ lower than control $(0 \mathrm{kGy})$, whereas the average FE of N95-3M masks following all GIR doses $(0.5-15 \mathrm{kGy})$ were significantly lower than control $(P \leq 0.025)$. Interestingly, no significant differences $(P>0.05)$ were observed between typical and low dose rates GIR regarding their effects on FE of both masks.

In terms of evaluating the effect of low dose rate GIR on the physical structure of FFRs, no signs of visible changes or damages were observed. However, microscopic images (using ZEISS Axio Vert.A1 microscope, ZEISS, Germany) of the fiber layers of both masks were snapped following 0, 0.5, 5 and $15 \mathrm{k}$ Gy. The images showed some unusual micro holes in the irradiated fabrics compared to the control (Fig. 3). These holes may have resulted from alterations in polymer homogeneity caused by GIR, such as polymer clustering, cracking, and degradation, which may explain the instability of both masks at small PSs $\leq 1 \mu \mathrm{m}$ following GIR.

SARS-CoV-2 RNA detection using RT-qPCR assay. SARS-CoV-2 RNA stability following incubation at room temperature $(R T)$ versus $-80^{\circ} \mathrm{C}$. Results showed that the viral E Gene RNA was detected in all samples at mean cycle threshold $(\Delta \mathrm{Ct})$ values between 19.3 and 22.9 (Fig. 4). Interestingly, incubation of SARS-CoV-2 RNA samples at RT, as compared to $-80^{\circ} \mathrm{C}$, for 48 and $96 \mathrm{~h}$ had no significant effect on RNA detectability (Ttest, two-tailed $P$-values $=0.713$ and 0.467 , respectively). In addition, there were no significant differences in $\mathrm{Ct}$ values between 0,48 and $96 \mathrm{~h}$ (RT along with $\left.-80^{\circ} \mathrm{C}\right)$ of incubation time $(P=0.293$, parametric one-way repeated measures analysis of variance "RM-ANOVA").

SARS-CoV-2 RNA stability following gamma irradiation. The effect of the GIR $(0.5088 \mathrm{kGy} / \mathrm{h})$ doses (0 to 50 $\mathrm{kGy}$ ) on the detectability of SARS-CoV-2 RNA was assessed in 2 viral genes, envelope (E) and RNA dependent RNA polymerase 4 (RdRp4). Results of the respective $\Delta$ Ct values are presented in Fig. 5. Representative images of RT-qPCR results for both genes are presented in Fig. 6. Obviously, the $\Delta$ Ct detection threshold increased with increasing irradiation doses, indicating progressive radiation-induced degradation of viral RNA. For both 


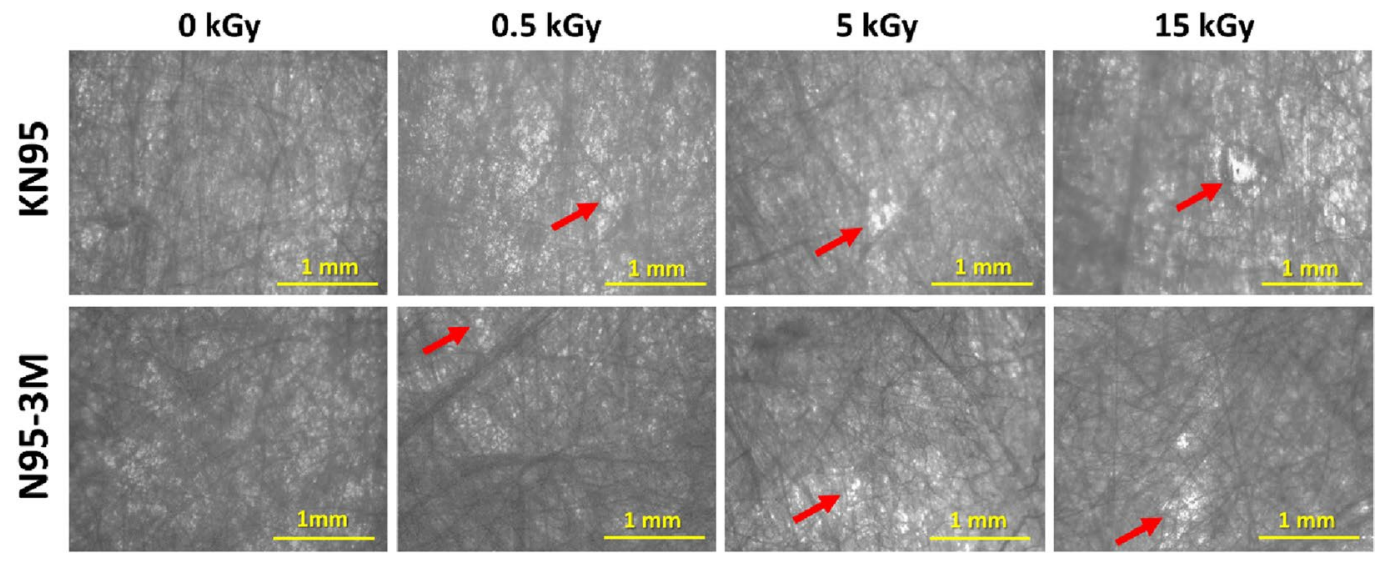

Figure 3. Representative microscopic images of KN95 and N95-3 M masks showing fabrics after 0, 0.5, 5 and $15 \mathrm{kGy}$ low dose rate gamma irradiation $(0.5088 \mathrm{kGy} /$ hour$)$. Arrows indicate physical changes (e.g. holes) within masks' fabrics resulting from alteration in polymer homogeneity following irradiation. Photomicrographs are at $5 \times$ magnification where scale bars show $1 \mathrm{~mm}$.

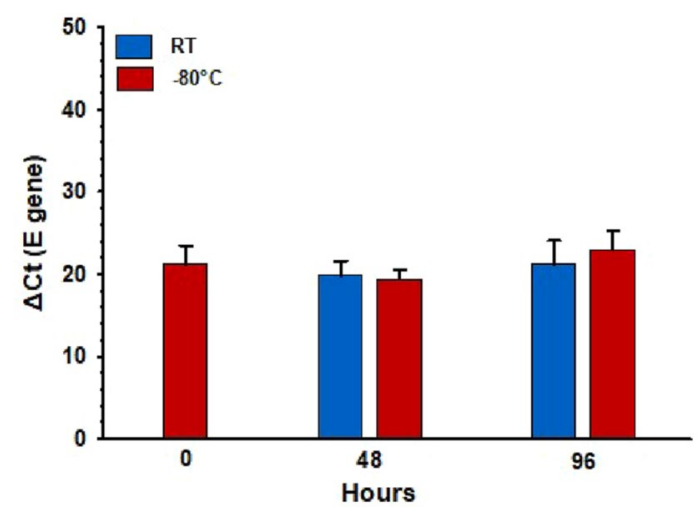

Figure 4. Effect of incubation time at room temperature (RT) and $-80^{\circ} \mathrm{C}$ on the detection of SARS-CoV-2 RNA E gene. No significant difference was observed between incubation at RT versus -80 or between different incubation times $(P \geq 0.293)$. $\Delta$ Ct: delta cycle threshold in RT-qPCR test. Bars represent the mean and error bars indicate the standard deviation.

genes, the RM-ANOVA indicated an overall statistically significant difference $(P<0.001)$ in the mean $\Delta$ Ct values between the different radiation doses.

Based on the $\mathrm{E}$ gene detection, results of the pairwise multiple comparison (Bonferroni $\mathrm{t}$-test) showed that GIR at doses of $15(\Delta \mathrm{Ct}=27.4), 20(\Delta \mathrm{Ct}=31.2), 25(\Delta \mathrm{Ct}=35.0), 30(\Delta \mathrm{Ct}=39.5)$ and $40(\Delta \mathrm{Ct}=42.0) \mathrm{kGy}$ exhibited a significant $(P \leq 0.001)$ increase in the mean $\Delta \mathrm{Ct}$ values compared to control $(\Delta \mathrm{Ct}=22.8)$. Meanwhile, no significant difference $(P>0.22)$ was observed between $1(\Delta \mathrm{Ct}=21.9), 5(\Delta \mathrm{Ct}=23.3)$ and $10(\Delta \mathrm{Ct}=25.1)$ as compared to the control 0 Gy. Note that the SARS-CoV-2 RNA E gene was only detected in 1 out of 5 samples (i.e. $20 \%$ ) following 30 ( $\Delta \mathrm{Ct}$ value of 39.5$)$ and $40(\Delta \mathrm{Ct}$ value of 42.0$) \mathrm{kGy}$, with no detection was observed at 50 kGy (Fig. 5-A).

Likewise, the results of the pairwise multiple comparison (Bonferroni t-test) of RdRp4 gene detection showed that GIR at doses of $20(\Delta \mathrm{Ct}=31.3)$ and $25(\Delta \mathrm{Ct}=39.6) \mathrm{kGy}$ caused a statistically significant $(P<0.001)$ increase in the mean $\Delta \mathrm{Ct}$ values compared to $0 \mathrm{~Gy}$ control $(\Delta \mathrm{Ct}=22.1)$. Meanwhile, no significant difference $(P>0.137)$ was observed between $1(\Delta \mathrm{Ct}=21.2), 5(\Delta \mathrm{Ct}=22.4), 10(\Delta \mathrm{Ct}=24.3)$ and $15(\Delta \mathrm{Ct}=26.8)$ as compared to the control 0 Gy. Furthermore, the RdRp4 gene was not detected in all 5 samples following 30, 40 and 50 kGy (Fig. 5-B).

\section{Discussion}

We have evaluated the FE of N95-3M and KN95 following GIR as a potential decontamination method for subsequent reuse of FFRs as a crisis strategy in case of N95 masks shortage ${ }^{3}$. The results showed that the KN95 mask retained an initial FE of $\geq 99.7 \%$ at a PS of $0.3 \mu \mathrm{m}$ or larger, whereas the N95-3M mask showed a range of FE between $77.1 \%$ at $0.3 \mu \mathrm{m}$ and $98.7 \%$ at $5 \mu \mathrm{m}$ (Fig. 1). The overall means FE of KN95 masks were significantly higher $(P=0.022)$ than N95-3M masks. This agrees with a recent study showing an average KN95 FE of $96.7 \%$ at PS between 0.03 and $0.5 \mu \mathrm{m}^{33}$. In reasonable agreement with our results, Cramer et al. found that control 
a SARS-CoV-2 E Gene

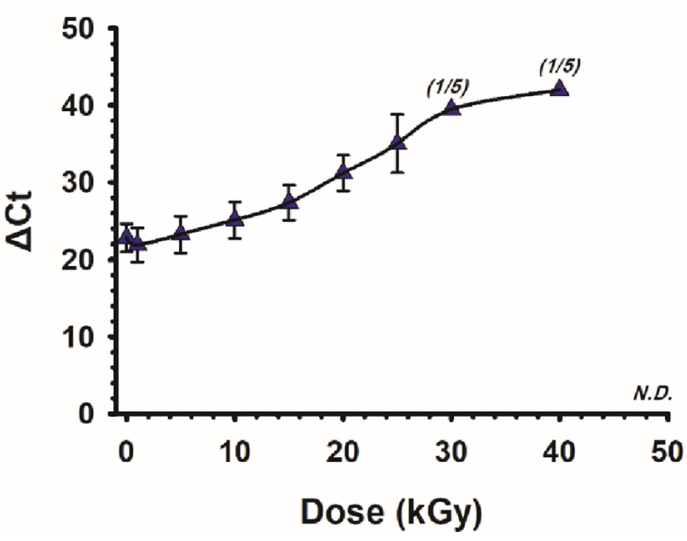

b SARS-CoV-2 RdRp4 Gene

Figure 5. Delta Ct values of SARS-CoV-2 RNA samples irradiated with gamma irradiation. Five samples were treated with 1, 5, 10, 15, 20, 25, 30, 40 and $50 \mathrm{kGy}$. Detection of SARS-CoV-2 RNA was performed using RT-qPCR based on both E (a) and RdRp4 genes (b). Statistically, both genes showed an overall significant $(P<0.001)$ increase in $\Delta \mathrm{Ct}$ values with increased doses of gamma radiation. Pairwise comparison for $\mathrm{E}$ gene (0 kGy vs. 15, 20, 25, 30 and $40 \mathrm{kGy})$ were significant $(P<0.001)$. Pairwise comparison for RdRp4 gene $(0 \mathrm{kGy}$ vs. 20 and $25 \mathrm{kGy})$ were significant $(P<0.001)$. 1/5: one sample out of 5 was detected. N.D.: not detected. Symbols represent the mean and error bars indicate the standard deviation.

\section{Amplification Plot}

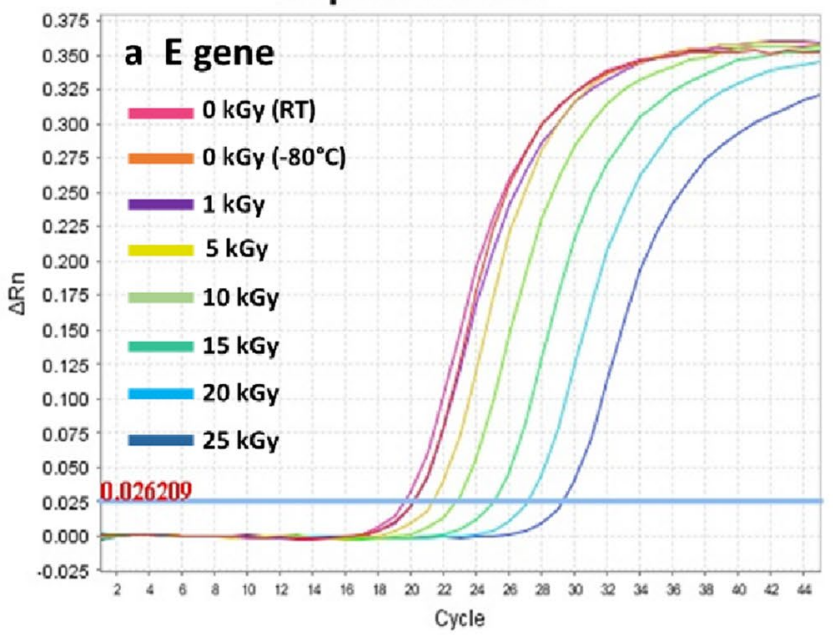

Amplification Plot

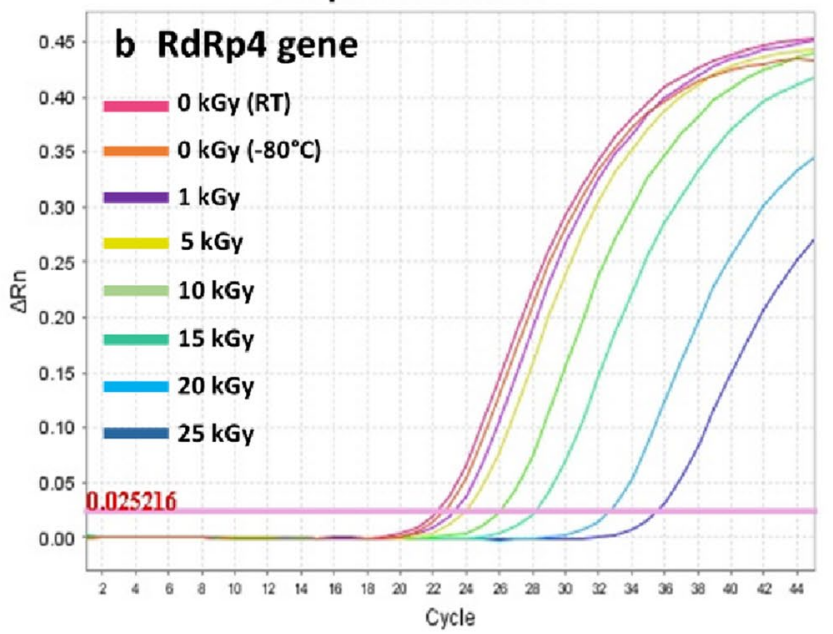

Figure 6. Representative images of RT-qPCR results of SARS-CoV-2 RNA E (a) and RdRp4 (b) genes detection following different gamma irradiation doses ranging from 1 to $25 \mathrm{~Gy}$.

N95-3M masks displayed an initial FE of $86.6 \%, 88.4 \%$ and $87.7 \%$ at PSs of $0.3,0.5$ and $1 \mu \mathrm{m}$, which were $77.1 \%$, $79.7 \%$ and $90.9 \%$, respectively in our results ${ }^{6}$. It is worth pointing out that the latter study used the same FE evaluation parameters assessment used in our study in terms of using the PM air as a source of the particles, using the same AeroTrak particle counter (TSI, Model 9306) as a particle counter and using the same air filter face velocity $(0.4 \mathrm{~m} / \mathrm{s})$.

The current study hypothesized that the adverse effect of GIR on FFRs could be minimized by using low dose rate GIR. This was suggested from the literature where a potential association between increasing GIR dose rate and decreasing $\mathrm{FE}^{6,16-19}$. Furthermore, a recent consultancy meeting on "radiation effects on polymer materials" organized by The International Atomic Energy Agency (IAEA) recommended expanding the research on the GIR dose rate and its potential impact on minimizing polymer alterations, stating that "it was determined that published studies on dose rate effects on polymers are largely lacking"34. Our results showed that the FE of KN95 masks was almost stable at PSs of 2 and $5 \mu \mathrm{m}$ following GIR of either typical or low (FE $=98.3-100.0 \%)$ dose rates (Fig. 2-A). However, a decrease in FE of KN95 masks at PSs between 0.3 and $1 \mu \mathrm{m}$ was observed following typical or low dose rates, reaching $88.0 \%$ and $81.5 \%$, respectively. For N95-3M masks, our results showed that the FE value at PSs of $5 \mu \mathrm{m}$ (94.3-98.7\%) was more stable than other PSs following typical or low dose rates GIR 


\begin{tabular}{|c|c|c|c|c|c|c|c|c|}
\hline Study & $\begin{array}{l}\text { Radiation Dose } \\
\text { (kGy) }\end{array}$ & Dose rate $(\mathrm{kGy} / \mathrm{h})$ & particle size $(\mu \mathrm{m})$ & $\begin{array}{l}\text { filter face velocity } \\
(\mathrm{m} / \mathrm{s})\end{array}$ & Flow rate $(\mathrm{L} / \mathrm{min})$ & $\begin{array}{l}\text { Ambiance } \\
\text { (aerosol vs PM } \\
\text { air) }\end{array}$ & Particle counter & Reference \\
\hline 1 & 1,10 and 50 & 2.2 & $0.1,0.5$ and 1 & 0.4 & 2.8 & APM & $\begin{array}{l}\text { Aerotrak } 9306 \\
\text { (TSI) }\end{array}$ & 6 \\
\hline $2 * *$ & 15 and 25 & 1.94 & $0.3,0.5$ and 1 & 0.5 and 2.6 & 20 and 90 & Aerosol & $\mathrm{OPC}^{\star}$ & 16 \\
\hline $3^{* *}$ & 15 and 25 & 1.94 & $\begin{array}{l}0.3,0.5,1,3,5 \\
\text { and } 10\end{array}$ & 0.50 & 20 and 90 & Aerosol & $\mathrm{OPC}^{\star}$ & 17 \\
\hline 4 & 15 and 25 & 1.94 & $0.3,0.5,1$ and 5 & 0.50 & 20 and 90 & Aerosol & $\mathrm{OPC}^{\star}$ & 18 \\
\hline 5 & 25 & 1.8 & $0.075-0.3^{* * *}$ & 0.17 & 100 & Aerosol & \begin{tabular}{|l}
$\begin{array}{l}\text { Aerotrak } 8020 \\
\text { (TSI) }\end{array}$ \\
\end{tabular} & 19 \\
\hline The current study & $\begin{array}{l}0.5,1,2,3,4,5,7.5 \\
\text { and } 15\end{array}$ & 1.65 and 0.5088 & $\begin{array}{l}0.3,0.5,0.7,1,2 \\
\text { and } 5\end{array}$ & 0.4 & 2.8 & APM & $\begin{array}{l}\text { Aerotrak } 9306 \\
\text { (TSI) }\end{array}$ & NA \\
\hline
\end{tabular}

Table 2. Comparison between the parameters used in five studies investigating the filtration efficiency of FFRs following gamma irradiation. ${ }^{\star}$ Optical Particle Counter (Model 1.108, Grimm Aerosol Technik, Germany). ${ }^{* *}$ Preprinted study. ${ }^{* *}$ Continuous measurement.

(Fig. 2-B). Overall, no significant differences $(P>0.05)$ were observed between typical and low dose rates GIR in terms of their effects on FE of each mask.

This is the first study to investigate the effect of GIR on KN95 masks as well as the first to compare the effect of different dose rates of GIR on FE of FFRs. Only five studies, with two of them are preprinted manuscripts, investigated the effect of GIR on FFRs using different evaluation parameters including GIR dose rate, particle size, air filter face velocity, flow rate, particle counter and source of particles (Table 2) ${ }^{6,16-19}$. In disagreement with our findings, Cramer and colleagues observed a $67.0 \%, 54.5 \%$ and $22.1 \%$ decrease in FE of N95-3M masks, at PSs of $0.3,0.5$ and $1 \mu \mathrm{m}$ following $1 \mathrm{kGy}(2.2 \mathrm{kGy} / \mathrm{h})^{6}$. In comparison, there were only $9.9 \%, 10.1 \%$ and $6.9 \%$ for the typical dose rate and $7.7 \%, 11.0 \%$, and $8.6 \%$ for the low dose rate, respectively (Supplementary Table S2) in our study. It is worthwhile noting that the GIR dose rate used was higher $(2.2 \mathrm{kGy} / \mathrm{h})$ than those used in our study. Another study also showed a 50\% decrease in FE at PS of $0.075 \mu \mathrm{m}$ of two other FFRS types following a single dose of $25 \mathrm{kGy}(1.8 \mathrm{kGy} / \mathrm{h})$, a dose that was not examined in our study ${ }^{19}$. Furthermore, the study showed that GIR exhibited significant changes in electrostatic charges of the filtration layer within the FFRs.

Furthermore, three reports showed mild adverse GIR effect $(<50 \%$ decrease in FE) on FFRs, which are comparable with our findings ${ }^{16-18}$. The first preprint showed that the average FE of N95 masks at $\geq 0.3 \mu \mathrm{m}$ was decreased by $29.6 \%$ following $15 \mathrm{kGy}$, while it was $12.9 \%$ in our results (Supplementary Table S1) ${ }^{16}$. The second preprint showed a $\sim 28 \%$ decrease in $\mathrm{FE}$ at $0.3 \mu \mathrm{m}$ following $15 \mathrm{kGy}$, while it was $19.75 \%$ in our findings ${ }^{17}$. However, the latter preprint showed no effect of GIR on FE at $5 \mu \mathrm{m}$, which differs from our findings as $\sim 4.5 \%$ decreases in FE was observed (Supplementary Table S1). The third preprint showed that GIR exhibited a 3.7\% decrease in $\mathrm{FE}$ at $1 \mu \mathrm{m}$ following $15 \mathrm{kGy}$, while it was $11 \%(9.6-12.4)$ in our results ${ }^{18}$. Taken all the five studies together, GIR had an adverse effect on FE of FFRs although they showed variations in FE data. These variations may be explained by the influence of various factors on the FE assessment such as FE evaluation parameters, GIR dose rate and FFR types.

To try to minimize the adverse effect of GIR on the fabrics of FFEs, two suggestions related to irradiation conditions could help preserve FFRs efficiency. The first suggestion is to irradiate the FFRs in a free-oxygen (e.g. nitrogen or vacuum) container ${ }^{34,35}$. The structural destruction of the PP (the main component of the FFRs filter fabrics) following GIR is particularly noticeable in the presence of air due to the oxidative damage of the PP's structure ${ }^{12}$. However, applying this idea should take into consideration that the structural components of viruses, such as nucleic acids, protein and lipid, could be more resistant to radiation in the anoxic than aerobic conditions ${ }^{36,37}$. The second suggestion is to irradiate the FFEs at a low-temperature atmosphere to decrease PP cross-linking within FFEs during the irradiation process ${ }^{38}$. Although cold-irradiation processing may protect against PP damage, it can also limit damage to the pathogens, the target of the irradiation process ${ }^{39,40}$.

Although our observation did not notice any visible changes in the FFRs structure following GIR, microscopic changes were observed within masks' materials, which may explain the FE instability following GIR (Fig. 3). These changes were expected as several studies reported that GIR exhibited significant physical changes in the PP, the main component in the filtration layers of FFRs ${ }^{12-15}$. Therefore, further monitoring of the potential changes in physical structure and electrostatic charge status of decontaminated FFRs should be considered. In terms of evaluating the fit factor of the irradiated FFRs, previous studies showed that GIR has no effect on the fit factor of FFRs although it degrades FFRs' $\mathrm{FE}^{6,16,17}$. In addition, a recent IAEA report agreed with the latter studies and showed that $24 \mathrm{kGy}$ has no effect on the fit factor on irradiated FFRs ${ }^{41}$.

Interestingly, results showed that the viral E Gene RNA was detected at RT up to $96 \mathrm{~h}$, with no significant difference compared to $-80^{\circ} \mathrm{C}$ incubation (Fig. 4). Our data also showed that $\mathrm{E}$ and RdRp4 SARS-CoV-2 genes (Fig. 5) could be constantly detected up to $25 \mathrm{kGy}$, and randomly at $30-40 \mathrm{kGy}$, but not at $50 \mathrm{kGy}$. Two reports so far evaluated the ability of GIR to inactivate SARS-CoV-2 using the median tissue culture infectious dose $\left(\mathrm{TCID}_{50}\right)$ assay ${ }^{30,31}$. Both studies found that the cultured active SARS-CoV-2 was completely inactivated by GIR at the dose of $10 \mathrm{kGy}$. However, Leung et al. found that the $\mathrm{E}$ and the nucleocapsid (NP) SARS-CoV-2 genes can still be detected following $50 \mathrm{kGy}$ using RT-qPCR assay ${ }^{30}$. The large difference between the GIR dose needed to observe complete viral inactivation ( $10 \mathrm{kGy}$ ) and to achieve complete viral RNA degradation (50 kGy) may emanate from the inherent characteristics of each assay. Although SARS-CoV-2 genes were still detectable at 40 
kGy by RT-qPCR, it does not necessarily mean that RNA was intact, and the viral particle of SARS-CoV-2 was still infectious. The influence of GIR on other biological factors rather than RNA, such as protein and lipids, seems limited as a study showed that the integrity of viral morphology and protein structures of coronaviruses were preserved following $10 \mathrm{kGy}^{42}$.

In conclusion, the KN95 mask showed a higher initial FE than the 3M-N95 masks. Irradiated KN95 and N95-3M masks showed microstructural changes within masks' fabrics associated with dose-dependent substantial reductions $(\leq 18.5 \%)$ in $\mathrm{FE}$ at small particle sizes $(0.3-2 \mu \mathrm{m})$ and moderate reductions $(\leq 4.5 \%)$ at large $(5$ $\mu \mathrm{m})$ particle size, the size of the most suspected droplets implicated in COVID-19 transmission. GIR dose rate does not seem to be an influencing factor on the FE of irradiated FFRs. Incubation for 4-days at room temperature has no effect on SARS-CoV-2 detectability using RT-qPCR assay. The mean cycle threshold $(\Delta \mathrm{Ct})$ of viral RNA detection increased with increasing GIR doses with an absence of detection at very high doses.

\section{Materials and methods}

Authors confirm that all methods were carried out in accordance with relevant guidelines and regulations.

Filtering facepiece respirators (FFRs). This study used two FFRs types: KN95 and 3M-N95 masks. The KN95 masks (molded shape) were manufactured by ZhongShan XiaoLan YiShuai Garment Factory, Zhongshan, China, with a lot number of A12199, and have met the Chinese standards for FFRs ${ }^{43}$. The 3M-N95 NIOSHapproved masks were manufactured by $3 \mathrm{M}$ North American Company with a model number of 8210 and lot number of A12199². Although NIOSH has not approved KN95 masks to be used as FFRs, it recommended the KN95 to be used in the medical settings when NIOSH-approved masks are unavailable ${ }^{44}$.

Gamma irradiation sources. This study used two GIR sources representing two different dose rates: typical and low. The first GIR source is a typical dose rate source located at the Nuclear Science Research Institute, King Abdulaziz City for Science and Technology (KACST), Riyadh, Saudi Arabia. The institute uses a Gamma Cell 220 cobalt-60 source (MDS Nordion, Ottawa, Canada) with a dose rate of $1.65 \mathrm{kGy} / \mathrm{h}$. The second GIR source is an industrial low dose rate source located at the Gamma Irradiation Facility (GIF), Biomedical Physics Department, King Faisal Specialist Hospital and Research Centre, Riyadh, Saudi Arabia. The GIF uses a cobalt-60 gamma source (Puridec Irradiation Technology, CHESHAM, Buckinghamshire, England) with a current dose rate of $0.5088 \mathrm{kGy} / \mathrm{h}$. The typical GIR dose rate used in FFRs decontamination ranges between 1.8 and $2.2 \mathrm{kGy} / \mathrm{h}^{6,16-19}$. The first (typical dose rate) GIR source was used to irradiate FFRs (0.5-15 kGy) only, while the second (low dose rate) GIR source was used to irradiate FFRs (0.5-15 kGy) and SARS-CoV-2 RNA samples (1-50 kGy). The GIR doses ranged from 0 to $50 \mathrm{kGy}$ and the required time needed to deliver the doses extended up to $98.16 \mathrm{~h}$ for the highest dose.

Filtration efficiency (FE) assessment of filtering facepiece respirators (FFRs). Filtration efficiency (FE) measurement. The FE measurement used in this study is an in-house method that was previously described $^{45}$. Briefly, a custom-designed air duct was manufactured to measure the FE of different FFRs types using the PM air as a source of the measured particles. The overall dimensions of the air duct are 19-cm-long, 14-cm-wide and 12-cm-high. The air duct consists of two parts, head and tail, that can be tightly joined together by three mold bolts to squeeze a filter in a sandwich manner, with no air leak present between both parts. The head of the air duct is connected to an AeroTrak particle counter (TSI, Model 9306) that counts particles with sizes of $0.3,0.5,0.7,1,2$ and $5 \mu \mathrm{m}$ at a flow rate of 2.8 liters/minute $(\mathrm{L} / \mathrm{min})$. The tail of the air duct is connected to an electrical fan that flows the PM air through the air duct tail to give a face velocity of $0.4 \mathrm{~m} / \mathrm{s}$; measured by Velocicalc Air Velocity Meter 9545 (TSI, product ID\# 9545-A).

Initial filtration efficiency (FE) of FFRs. A total of 10 FFRs of each type (N95-3M and KN95) were subjected to FE evaluation. The 10 FFRs will be used later as controls ( $0 \mathrm{kGy})$ for FFRs irradiated with either low dose GIR (5 FFRs) or typical dose rate GIR (5 FFRs).

The particle number concentration of the PM air was assessed at least 5 times before FFRs assessment. For each PS, FE was calculated using the following formula:

$$
F E(\%)=100-\left(\frac{\text { number of penetrated particles }}{\text { average number of particles in air }} \times 100\right)
$$

Filtration efficiency (FE) of FFRs following gamma irradiation. For each source of GIR (typical and low dose rates), 5 FFRs of each type (KN95 and N95-3M) were exposed to 8 different radiation doses $(0.5,1,2,3,4,5,7.5$ and $15 \mathrm{kGy}$ ) with $0 \mathrm{kGy}$ as a control. In total, 45 masks of each type of FFRs were used in the study.

Detection of SARS-CoV-2 RNA following gamma irradiation. The stability of 5 SARS-CoV-2 RNA samples against GIR doses ( $0-50 \mathrm{kGy}$ ) was evaluated using the RT-qPCR assay targeting the E and RdRp4 SARSCoV-2 genes.

SARS-CoV-2 samples collection and ethical considerations. Nasopharyngeal swabs were obtained from COVID19 patients between May and July 2020. The samples were collected for diagnosis and archived for research purposes. The Institutional Review Board (IRB) at King Faisal Specialist Hospital and Research Centre (KFSH\&RC), 
Riyadh, Saudi Arabia (RAC Approval\# 2200031) has approved the study. Five SARS-CoV-2 positive samples were randomly retrieved, anonymized, coded and used in this study. The IRB granted a waiver for obtaining informed consent owing to the use of anonymized archived samples.

Samples processing and RNA extraction. The five nasopharyngeal swabs were submerged in viral transport medium for diagnostic analysis in the microbiology laboratory at the Department of Pathology, KFSH\&RC, Riyadh, Saudi Arabia. Then, aliquots of leftover samples were stored at $-80^{\circ} \mathrm{C}$ until viral RNA extraction in a biosafety level-3 research laboratory. Viral RNA extraction was performed using an in-house automated RNA extraction protocol ${ }^{46}$.

SARS-CoV-2 RNA stability following incubation at room temperature $(R T)$ versus $-80^{\circ} \mathrm{C}$. As both GIR facilities used do not have cooling systems, pre-irradiation optimization experiments were performed to evaluate the effect of RT incubation $(0,48$ and $96 \mathrm{~h})$ on the stability of SARS-CoV-2 RNA using RT-qPCR assay. Three SARSCoV-2 RNA samples were thawed from $-80^{\circ} \mathrm{C}$, then each sample was aliquoted into 3 test tubes, and incubated for 0,48 or $96 \mathrm{~h}$. RT-qPCR assay (E gene) was performed directly after each time point for SARS-CoV-2 RNA detection.

Effect of gamma irradiation on SARS-CoV-2 RNA detection. Each of the 5 RNA samples of COVID-19 patients were individually aliquoted into a total of 11 tubes; 2 tubes were allocated for controls without irradiation $(0$ kGy) kept either at RT or at $-80^{\circ} \mathrm{C}$ for the duration of the experiment, while 9 tubes were exposed to 9 different low dose rate GIR doses $(1,5,10,15,20,25,30,40$ and $50 \mathrm{kGy})$. This experiment was initially performed with irradiation doses of 1, 5, 10, 15, 20 and $25 \mathrm{kGy}$. As SARS-CoV-2 E and RdRp4 genes were still detectable at 25 $\mathrm{kGy}$ dose, we have added 30, 40 and $50 \mathrm{kGy}$ along with two samples (RT and $-80^{\circ} \mathrm{C}$ ) were added as controls.

Reverse transcription quantitative real-time polymerase chain reaction (RT-qPCR). The TAQPATH COVID-19 CE-IVD RT-PCR reverse transcription quantitative real-time polymerase chain reaction kit (Thermo Fisher Scientific: A48102) was used as described previously ${ }^{47}$. The primers of E and RdRp4 SARS-CoV-2 genes were selected to examine the presence of SARS-CoV-2 RNA based on WHO and CDC recommendations for patients' testing and diagnosis (Supplementary Table S3), which were adapted from Charité Institute of Virology, Pasture Institute, Paris, France ${ }^{48}$. The RT-qPCR cycling conditions, the final concentrations of the reaction components in the master mix used in the study are summarized in Supplementary Tables S4 and S5, respectively.

Statistical analysis. The paired t-test was used to examine the overall statistical differences in the initial FE between KN95 and N95-3M masks. The t-test was applied to test for significant differences in the initial FE between various PSs within each mask as well as to examine the statistical differences in the mean $\Delta \mathrm{Ct}$ values between RNA samples following RT and $-80^{\circ} \mathrm{C}$ incubations. The parametric one-way repeated measures analysis of variance (RM-ANOVA) was used to test significant differences in the mean FE between irradiated and non-irradiated masks, as well as in the mean $\Delta \mathrm{Ct}$ values between irradiated and non-irradiated CoV-SARS-2 RNA samples. The Bonferroni t-test was used to correct for the pairwise multiple comparisons in the RMANOVA when appropriate. All the statistical Analyses were performed using SigmaPlot version 14.5 for Windows (SPSS, Chicago, USA). A $P$-value $<0.05$ is considered statistically significant.

Received: 27 July 2021; Accepted: 23 September 2021

Published online: 06 October 2021

\section{References}

1. Devices, R. P. Final rules and notice. Fed. Reg. 60, 30335-30398 (1995).

2. Centers for Disease Control and Prevention (CDC). NIOSH-Approved N95 Particulate Filtering Facepiece Respirators. https://www. cdc.gov/niosh/npptl/topics/respirators/disp_part/n95listl.html (2021).

3. Centers for Disease Control and Prevention (CDC). Recommended Guidance for Extended Use and Limited Reuse of N95 Filtering Facepiece Respirators in Healthcare Settings, https://www.cdc.gov/niosh/topics/hcwcontrols/recommendedguidanceextuse.html\# ref19 (2020).

4. Rebmann, T., Carrico, R. \& Wang, J. Physiologic and other effects and compliance with long-term respirator use among medical intensive care unit nurses. Am. J. Infect. Control 41, 1218-1223 (2013).

5. Chin, A. et al. Stability of SARS-CoV-2 in different environmental conditions. medRxiv (2020).

6. Cramer, A. et al. Assessment of the qualitative fit test and quantitative single-pass filtration efficiency of disposable N95 Masks following gamma irradiation. JAMA Netw. Open 3, e209961-e209961 (2020).

7. Centers for Disease Control and Prevention (CDC). Implementing Filtering Facepiece Respirator (FFR) Reuse, Including Reuse after Decontamination, When There Are Known Shortages of N95 Respirators. https://www.cdc.gov/coronavirus/2019-ncov/hcp/ppe-strat egy/decontamination-reuse-respirators.html (2020).

8. Rodriguez-Martinez, C. E., Sossa-Briceño, M. P. \& Cortés-Luna, J. A. Decontamination and reuse of N95 filtering facemask respirators: A systematic review of the literature. Am. J. Infect. Control (2020).

9. Derraik, J. G., Anderson, W. A., Connelly, E. A. \& Anderson, Y. C. Rapid review of SARS-CoV-1 and SARS-CoV-2 viability, susceptibility to treatment, and the disinfection and reuse of PPE, particularly filtering facepiece respirators. Int. J. Environ. Res. Public Health 17, 6117 (2020).

10. Kierat, W. et al. The use of UVC irradiation to sterilize filtering facepiece masks limiting airborne cross-infection. Int. J. Environ. Res. Public Health 17, 7396 (2020). 
11. Brinston, R. \& Wilson, B. Converting to gamma-radiation sterilization: An overview for medical device manufacturers. Med. Device Technol. 4, 18-22 (1993).

12. Khang, G., Lee, H. B. \& Park, J. B. Radiation effects on polypropylene for sterilization. Bio-Med. Mater. Eng. 6, 323-334 (1996).

13. Zhang, X. \& Cameron, R. The morphology of irradiated isotactic polypropylene. J. Appl. Polym. Sci. 74, 2234-2242 (1999).

14. Chawla, K. Fibrous Materials. (Cambridge University Press, 2016).

15. Harrell, C. R., Djonov, V., Fellabaum, C. \& Volarevic, V. Risks of using sterilization by gamma radiation: The other side of the coin. Int. J. Med. Sci. 15, 274 (2018).

16. Kumar, A. et al. Effect of Gamma Sterilization on Filtering Efficiency of Various Respiratory Face-Masks. https://www.medrxiv. org/content/https://doi.org/10.1101/2020.06.04.20121830v1.full.pdf (2020).

17. Kumar A. B. B., Sangeetha, D. N., Subramanian, V., \& Venkatraman, B. Evaluation of filtration efficacy of various types of facemasks using ambient and PAO aerosols following with different sterilization methods. https://www.medrxiv.org/content/https:// doi.org/10.1101/2020.10.23.20218073v1 (2020).

18. Kumar, A. et al. Quantitative performance analysis of respiratory facemasks using atmospheric and laboratory generated aerosols following with gamma sterilization Aerosol Air Qual. Res. 20 (2020).

19. DeAngelis, H. E. et al. Gamma radiation sterilization of N95 respirators leads to decreased respirator performance. PLoS ONE 16, e0248859 (2021).

20. Sullivan, R., Fassolitis, A. C., Larkin, E. P., Read, R. B. \& Peeler, J. T. Inactivation of thirty viruses by gamma radiation. Appl. Environ. Microbiol. 22, 61-65 (1971).

21. Thomas, F. et al. Gamma ray inactivation of some animal viruses. Can. J. Comp. Med. 45, 397 (1981).

22. Summers, W. C. \& Szybalski, W. Gamma-irradiation of deoxyribonucleic acid in dilute solutions: II. Molecular mechanisms responsible for inactivation of phage, its transfecting DNA, and of bacterial transforming activity. J. Mol. Biol. 26, 227-235 (1967).

23. Ward, R. L. Mechanisms of poliovirus inactivation by the direct and indirect effects of ionizing radiation. Radiat. Res. 83, 330-344 (1980).

24. Ohshima, H., Iida, Y., Matsuda, A. \& Kuwabara, M. Damage induced by hydroxyl radicals generated in the hydration layer of $\gamma$-irradiated frozen aqueous solution of DNA. J. Radiat. Res. 37, 199-207 (1996).

25. Elliott, L. H., McCormick, J. B. \& Johnson, K. M. Inactivation of Lassa, Marburg, and Ebola viruses by gamma irradiation. J. Clin. Microbiol. 16, 704-708 (1982).

26. Korystov, Y. N. Contributions of the direct and indirect effects of ionizing radiation to reproductive cell death. Radiat. Res., 228-234 (1992).

27. Hume, A. J. et al. Inactivation of RNA viruses by gamma irradiation: A study on mitigating factors. Viruses 8, 204 (2016).

28. Kumar, M. et al. Inactivation and safety testing of Middle East respiratory syndrome coronavirus. J. Virol. Methods 223, 13-18 (2015).

29. Feldmann, F., Shupert, W. L., Haddock, E., Twardoski, B. \& Feldmann, H. Gamma irradiation as an effective method for inactivation of emerging viral pathogens. Am. J. Trop. Med. Hyg. 100, 1275-1277 (2019).

30. Leung, A. et al. In vitro inactivation of SARS-CoV-2 using gamma radiation. Appl. Biosaf. 25, 157-160 (2020).

31. Jain, R. et al. Inactivation of SARS-CoV-2 by gamma irradiation. Indian J. Med. Res. 153, 196 (2021).

32. Darnell, M. E., Subbarao, K., Feinstone, S. M. \& Taylor, D. R. Inactivation of the coronavirus that induces severe acute respiratory syndrome SARS-CoV. J. Virol. Methods 121, 85-91 (2004).

33. Cai, C. \& Floyd, E. L. Effects of sterilization with hydrogen peroxide and chlorine dioxide solution on the filtration efficiency of N95, KN95, and surgical face masks.

34. The International Atomic Energy Agency (IAEA). IAEA Consultancy Meeting on "Radiation Effects on Polymer Materials". http:// www-naweb.iaea.org/napc/iachem/working_materials/IAEA\%20Consultancy\%20Meeting\%20Final\%20Report.pdf (2019).

35. Fintzou, A. T., Kontominas, M. G., Badeka, A. V., Stahl, M. R. \& Riganakos, K. A. Effect of electron-beam and gamma-irradiation on physicochemical and mechanical properties of polypropylene syringes as a function of irradiation dose: Study under vacuum. Radiat. Phys. Chem. 76, 1147-1155 (2007).

36. Lea, D., Smith, K. M., Holmes, B. \& Markham, R. Direct and indirect actions of radiation on viruses and enzymes. Parasitology 36, 110-118 (1944).

37. Pollard, E. In Advances in Virus Research Vol. 2, 109-151 (Elsevier, 1954).

38. Krause, B., Voigt, D., Häußler, L., Auhl, D. \& Münstedt, H. Characterization of electron beam irradiated polypropylene: Influence of irradiation temperature on molecular and rheological properties. J. Appl. Polym. Sci. 100, 2770-2780 (2006).

39. Powers, E. Physical determinants of radiation sensitivity in bacterial spores. Adv. Space Res. 3, 73-78 (1983).

40. Craven, E., Hasanain, F. \& Winters, M. Minimizing material damage using low temperature irradiation. Radiat. Phys. Chem. 81, 1254-1258 (2012).

41. The International Atomic Energy Agency (IAEA). Radiation Effective in Sterilizing Personal Protective Equipment Except For Respiratory Masks. https://www.iaea.org/newscenter/pressreleases/radiation-effective-in-sterilizing-personal-protective-equip ment-except-for-respiratory-masks-iaea (2020).

42. Beniac, D. R., Andonov, A., Grudeski, E. \& Booth, T. F. Architecture of the SARS coronavirus prefusion spike. Nat. Struct. Mol. Biol. 13, 751-752 (2006).

43. China, S. A. f. M. R. S. A. o. R. o. Respiratory Protection-Non-powered Air-Purifying Particle Respirator GB 2626-2019. https:// www.chinesestandard.net/PDF.aspx/GB2626-2006 (2019).

44. Centers for Disease Control and Prevention (CDC). Strategies for Optimizing the Supply of N95 Respirators. https://www.cdc.gov/ coronavirus/2019-ncov/hcp/respirators-strategy/index.html?CDC_AA_refVal=https\%3A\%2F\%2Fwww.cdc.gov\%2Fcoronavirus\% 2F2019-ncov\%2Fhcp\%2Frespirators-strategy\%2Fcrisis-alternate-strategies.html (2021).

45. Al-Hadyan, K. et al. In-house filtration efficiency assessment of vapor hydrogen peroxide decontaminated filtering facepiece respirators (FFRs). Int. J. Environ. Res. Public Health 18, 7169 (2021).

46. Al-Romaih, K. et al. Full-in-house method (FinHM) for SARS-COV-2 automated viral RNA extraction, followed by in-house 'primer-probe' based RT-qPCR detection; low cost mass testing. Am. J. Intern. Med. 9, 1-10 (2021).

47. Al-Saud, H. et al. Automated SARS-COV-2 RNA extraction from patient nasopharyngeal samples using a modified DNA extraction kit for high throughput testing. Ann. Saudi Med. 40, 373-381 (2020).

48. World Health Organization (WHO). Pasteur protocol: Real-time RT-PCR assays for the detection of SARS-CoV-2, https://www.who. int/docs/default-source/coronaviruse/real-time-rt-pcr-assays-for-the-detection-of-sars-cov-2-institut-pasteur-paris.pdf?sfvrsn= 3662fcb6_2 (2020).

\section{Acknowledgements}

We would like to thank King Abdulaziz City for Science and Technology (KACST) for funding this project, and the Nuclear Science Research Institute at KACST to facilitate the usage of the Cobalt-60 gamma rays (Gamma Cell 220). We would also like to thank Ahmad Nobah, Amr El-Sayed, Saad Bin Jamaan, Jeffrey Lindstrom, Layla Alharbi, Sawsan Falatah, Nawarh Faran and Hanan Alsaif for their assistance and the project's administrative 
and financial management. We acknowledge the support of KFSH\&RC administration and the cooperation of Research Centre Logistics and Supply Chain Management for their support.

\section{Author contributions}

Conceptualization, K.A.-H., G.A., M.A.-.M., S.A.-G., B.M. and R.A.; methodology, K.A.-H., N.A.-H., S.B.J., M.A.-G., A.A., I.A., R.B., K.A.-R. and M.A.-M.; investigation, K.A.-H., G.A., M.A.-G., K.A.-R. and B.M.; analysis, K.A.-H. and G.H.; resources and consultation B.M. and R.A.; writing original draft, K.A.-H. and G.A.; review and editing G.A., M.A.-M. and B.M..K.A.-H., G.A. are the corresponding authors for this manuscript as they were contributed equally.

\section{Funding}

This work was supported by King Abdulaziz City for Science and Technology (KACST) via The Fast Track Funding Path for Coronavirus Program (Project Number 5-20-01-558-0005; RAC\# 2200047).

\section{Competing interests}

The authors declare no competing interests.

\section{Additional information}

Supplementary Information The online version contains supplementary material available at https://doi.org/ 10.1038/s41598-021-99414-6.

Correspondence and requests for materials should be addressed to K.A.-H. or G.A.

Reprints and permissions information is available at www.nature.com/reprints.

Publisher's note Springer Nature remains neutral with regard to jurisdictional claims in published maps and institutional affiliations.

(c) (i) Open Access This article is licensed under a Creative Commons Attribution 4.0 International License, which permits use, sharing, adaptation, distribution and reproduction in any medium or format, as long as you give appropriate credit to the original author(s) and the source, provide a link to the Creative Commons licence, and indicate if changes were made. The images or other third party material in this article are included in the article's Creative Commons licence, unless indicated otherwise in a credit line to the material. If material is not included in the article's Creative Commons licence and your intended use is not permitted by statutory regulation or exceeds the permitted use, you will need to obtain permission directly from the copyright holder. To view a copy of this licence, visit http://creativecommons.org/licenses/by/4.0/.

(C) The Author(s) 2021 